\title{
Tumor-Derived Exosomal Long Noncoding RNAs as Promising Diagnostic Biomarkers for Prostate Cancer
}

\author{
Yu-Hui Wang ${ }^{\mathrm{a}}$ Jia Ji ${ }^{\mathrm{a}}$ Bi-Cheng Wang ${ }^{\mathrm{b}}$ Hao Chen ${ }^{\mathrm{b}}$ Zhong-Hua Yang ${ }^{\mathrm{c}}$ \\ Kun Wang ${ }^{d}$ Chang-Liang Luo ${ }^{a}$ Wu-Wen Zhanga Fu-Bing Wanga \\ Xiao-Lian Zhange
}

${ }^{a}$ Department of Laboratory Medicine, Zhongnan Hospital of Wuhan University, Wuhan, ${ }^{b}$ Department of Pathology, Zhongnan Hospital of Wuhan University, Wuhan, 'Department of Urology, Zhongnan Hospital of Wuhan University, Wuhan, 'Department of Laboratory Medicine, Hubei Cancer Hospital, Wuhan, ${ }^{e}$ State Key Laboratory of Virology. Hubei province Key Laboratory of Allergy and Immunerelated diseases, Medical Research Institute, Department of Immunology of Wuhan University School of Basic Medical Sciences, Wuhan, P.R. China

\section{Key Words}

Tumor-derived exosomes - Immunoaffinity-based isolation • Long noncoding RNA • Prostate cancer • Diagnostic biomarkers

\begin{abstract}
Background/Aims: Exosomal circulating long non-coding RNAs (IncRNAs) in blood are emerging as clinically useful and non-invasive biomarkers for tumor diagnosis. However, normal cells can also secrete exosomes, so it is a prerequisite to obtain tumor-derived exosomes for better understanding of their diagnostic impacts in cancer. In this study, a dual-antibodyfunctionalized immunoaffinity system was established to isolate exosomes and investigate their IncRNAs expression pattern and clinical significance in prostate cancer (PCa). Methods: A commercially available kit was used to isolate total exosomes, which were then purified by a dual-antibody-functionalized immunoaffinity system. RT-qPCR was performed to detect the expression of exosomal IncRNAs. Receiver operating characteristic (ROC) curves were plotted to assess the diagnostic value. Results: Expression levels of two IncRNAs in tumor-derived exosomes were significantly higher than those in total exosomes. The levels of SAP30L-AS1 were upregulated in benign prostatic hyperplasia (BPH), and SChLAP1 levels were significantly higher in PCa than in BPH and healthy individuals. The area under the ROC curve indicated that SAP30L-AS1 and SChLAP1 had adequate diagnostic value to distinguish PCa from controls. Two IncRNAs separately combined with prostate specific antigen (PSA) possessed a moderate ability for discrimination. SAP30L-AS1 expression level was related to PSA values and tumor invasion. SChLAP1 expression was significantly higher in patients with higher Gleason scores, and was also effective in differentiating between BPH and PCa when the concentration of PSA
\end{abstract}

Fu-Bing Wang and Xiao-Lian Zhang,

KARGER
Dpt. of Lab. Med., Zhongnan Hospital of Wuhan University, No 169 Donghu Road, Wuchang District, Wuhan 430071 (China) Dpt. of Immunol., Wuhan Uni., School of Med., 115 Donghu Road, Wuhan, 430071 (China)

E-Mail wfb20042002@sina.com; zhangxiaolian@whu.edu.cn 


\section{Cellular Physiology Cell Physiol Biochem 2018;46:532-545 \\ \begin{tabular}{l|l} 
DOI: 10.1159/000488620 & Ond Biochemistry \\
Published online: April 03, 2018 & $\begin{array}{l}\text { 2018 The Author(s). Published by S. Karger AG, Basel } \\
\text { www.karger.com/cpb }\end{array}$
\end{tabular} \\ Wang et al.: Diagnostic Potential of Tumor-Derived Exosomal LncRNAs in PCa}

was in the gray zone. Conclusion: The isolation of tumor-derived exosomes by dual-antibodyfunctionalized immunoaffinity systems and detection of their IncRNAs in plasma may lead to the identification of suitable biomarkers, with potential diagnostic utility.

(C) 2018 The Author(s)

Published by S. Karger AG, Basel

\section{Introduction}

Prostate cancer (PCa) is the most frequently diagnosed malignancy and also the second highest cause of leading cancer-related death in males in the United States [1]. The incidence of PCa varies remarkably among nations and races, which may be due in part to genetic differences [2,3]. Furthermore, the incidence is much higher in Western countries than in Asian countries. Once PCa patients eventually relapse and develop castration-resistant PCa (CRPC), which is more aggressive and incurable, the mortality rate increases significantly [4]. Although PSA screening has been widely applied for PCa diagnosis, there are obvious limitations. PSA may increase in BPH, leading to a high rate of false-positive diagnosis [5]. Thus, there is a need to identify novel non-invasive PCa-specific biomarkers in addition to PSA detection to improve diagnostic accuracy.

Long noncoding RNAs (lncRNAs), which are known to participate in various biological events such as cell differentiation, proliferation and death, are RNA transcripts of more than $200 \mathrm{bp}$ without protein coding function [6]. Over the past decade, accumulating evidence has demonstrated that IncRNAs modulate diverse processes in tumor suppression, metastasis, progression and clinical outcome in multiple types of cancers, including PCa $[7,8]$. For example, PCAT-1 is a transcriptional repressor and, a target of PRC2, so promoting cancer cell proliferation [9]. PCA3 is a prostate-tissue-specific lncRNA that is selectively overexpressed in PCa patients compared to healthy individuals [10]. Of the imprinting-associated IncRNAs, SChLAP1 has been extensively studied in PCa. SChLAP1 increases with progression of PCa and predicts poor prognosis of patients with PCa $[11,12]$. More importantly, these cancerrelated lncRNAs can be detected in body fluids, such as blood and urine $[13,14]$, which makes them ideal diagnostic and prognostic biomarkers for cancer patients. However, previous studies focused mainly on the diagnostic value of SChLAP1 in tissue [15].

Emerging evidence has demonstrated that exosomes contain a variety of proteins, DNA and RNA molecules including microRNAs and IncRNAs. Unlike naked circulating RNA molecules, RNA in exosomes is enriched in the circulatory system and protected from RNase degradation [16]. For instance, microRNA-1246, included in exosomes derived from breast cancer cells, promotes cell proliferation, invasion and drug resistance by targeting CCNG2 [17]. SAP30L-AS1 was one of the lncRNAs found in exosomes released from four PCa cell lines [18]. Exosomes are small lipid bilayer cup-shaped membrane vesicles of endocytic origin and with 50-90 nm in diameter $[19,20]$. They are released into the extracellular space upon fusion of multivesicular bodies with the plasma membrane $[20,21]$ and play important roles as cellular messengers to trigger diverse physiological and pathological responses and achieve cross-talk without direct contact with one another [22]. They have been found in a variety of biological fluids, such as blood [19], urine [23], saliva [24], milk [25] and bronchoalveolar lavage fluid [26] and are secreted by platelet [27], normal [28, 29] and tumor cells [30, 31]. Analyzing exosomes in the peripheral blood can therefore provide important information on the characteristics of parental cancer cells. Thus, exosomal lncRNAs are being considered as promising biomarkers in various cancers including gastric cancer [32], colorectal cancer [33], prostate cancer [34] and others [35].

Moreover, it has been demonstrated that exosomes derived from highly advanced cancer cells were enriched in tumor-associated markers, which can be captured by immune-affinity approaches [36]. Due to their high sensitivity and specificity, and because they are easy to obtain, exosomes have been considered a superior biomarker over conventional biomarkers in detecting different cancers. However, due to technical difficulties, capture of tumor-derived exosomes is still a challenge. Thus, development of a novel, efficient approach for isolating cancer-specific exosomes will shed light on the functions of tumor-derived exosomes.

\section{KARGER}




\section{Cellular Physiology Cell Physiol Biochem 2018;46:532-545 \begin{tabular}{l|l} 
DOI: 10.1159/000488620 & $\begin{array}{l}\text { O 2018 The Author(s). Published by S. Karger AG, Basel } \\
\text { www.karger.com/cpb }\end{array}$
\end{tabular} \\ Wang et al.: Diagnostic Potential of Tumor-Derived Exosomal LncRNAs in PCa}

In this study, a novel dual-antibody immunoaffinity-based method was developed to isolate tumor-derived exosomes from patients' plasma and to investigate whether lncRNAs in exosomes from plasma can serve as diagnostic biomarkers in PCa. Our approach was found to specifically enrich tumor-derived exosomes from total exosome samples isolated from plasma. Subsequently, tumor specific IncRNAs, SAP30L-AS1 and SChLAP1, inside tumor-derived exosomes were quantified by real-time RT-PCR and retrospectively analyzed, together with patients' clinical parameters. The area under the ROC curve indicated that SAP30L-AS1 and SChLAP1 had adequate diagnostic value to distinguish PCa from controls. Two IncRNAs separately combined with PSA possessed a moderate ability for discrimination. SAP30L-AS1 expression level was related to PSA values and tumor invasion. SChLAP1 expression was significantly higher in patients with higher Gleason scores and it was also effective in differentiating between BPH and PCa when the concentration of PSA was in the gray zone. Taken together, our dual-antibody immune-affinity approach could be an effective platform for enriching tumor-specific exosomes for diagnosis and for guidance as to potential therapies for treating different cancers.

\section{Materials and Methods}

\section{Cell culture}

Human PCa cell line LNCaP cells were purchased from the China Center for Type Culture Collection (CCTCC; Wuhan, China). Cells were grown in RPMI1640 (HyClone Laboratories, Logan, UT, USA) supplemented with 10\% fetal bovine serum (FBS) (Gibco; Thermo Fisher Scientifc, Inc., Waltham, MA, USA) and $1 \%$ penicillin-streptomycin (Beyotime, Shanghai, China) in a humidified atmosphere at $37^{\circ} \mathrm{C}$ with $5 \%$ $\mathrm{CO}_{2}$. Cells were harvested for analysis at $80-90 \%$ confluence.

\section{Plasma sample collection}

Peripheral blood samples were obtained from Zhongnan Hospital of Wuhan University, China, from September of 2016 to May of 2017. Control blood samples were obtained from 30 healthy volunteers with concentration of PSA less than $4 \mathrm{ng} / \mathrm{ml}$. Forty-six patients with BPH and 34 patients with PCa were enrolled in the study. The clinical parameters of all participants were available. All patients were Chinese and the characteristics of the studied subjects are summarized (for all online suppl. material, see www. karger.com/doi/10.1159/000488620) in Table S1. Biopsies from all patients were diagnosed and graded by board certified pathologists in Zhongnan Hospital. Peripheral blood samples were collected in EDTA tubes, then centrifuged at $2000 \times g$ for 5 minutes at $4^{\circ} \mathrm{C}$ to remove cells. The supernatants were transferred to microcentrifuge tubes and the remaining cells and debris were removed by centrifugation at $2,000 \times g$ for 20 minutes at $4^{\circ} \mathrm{C}$. Subsequently, the supernatants were transferred to a new tube without disturbing the pellet and centrifuged at $10,000 \times g$ for 20 minutes at $4^{\circ} \mathrm{C}$ to remove more debris. The supernatants were kept as plasma samples and stored at $-80^{\circ} \mathrm{C}$ until use.

\section{Total exosomes isolation}

Total exosomes were isolated from either conditioned cell culture medium or plasma samples. For exosome isolation from culture medium, cells were grown to $80 \%$ confluence in $75 \mathrm{~cm}^{2}$ flasks (Corning Incorporated, Corning, NY, USA), and then the culture medium was removed. The cells were washed with phosphate buffered saline (PBS) three times and cultured in FBS-free RPMI1640 medium for 48 hours. Subsequently, total cell culture medium was harvested from three $75 \mathrm{~cm}^{2}$ flasks and centrifuged at $2000 \times$ $g$ for 30 minutes to remove suspended cells and debris. Total Exosome Isolation Reagent (from cell culture media) (Invitrogen, Carlsbad, CA, USA) was used to isolate total exosomes following the manufacturer's instructions.

For exosomes isolation from plasma, approximately $400 \mu \mathrm{l}$ of plasma was thawed in a water bath at $37^{\circ} \mathrm{C}$. Exosomes were isolated using Total Exosome Isolation Reagent (from plasma) (Invitrogen, Carlsbad, CA, USA) according to the manufacturer's instructions. 


\section{Cellular Physiology Cell Physiol Biochem 2018;46:532-545 \begin{tabular}{c|c} 
DOI: 10.1159/000488620 & $\begin{array}{l}\text { O } 2018 \text { The Author(s). Published by S. Karger AG, Basel } \\
\text { www.karger.com/cpb }\end{array}$
\end{tabular} \\ Wang et al.: Diagnostic Potential of Tumor-Derived Exosomal LncRNAs in PCa}

\section{Transmission electron microscopic analysis}

Transmission electron microscopy (TEM) was performed at Wuhan Institute of Virology, China. Negative staining was applied for TEM measurement. Fresh exosomes were resuspended in PBS and $10 \mu \mathrm{l}$ of exosome sample was loaded on a 300-mesh copper grid (carbon coated), followed by room temperature drying for 5 minutes. In addition, $5 \mu \mathrm{l}$ of phosphotungstic acid was loaded onto the grid. Excess liquid was wicked off using filter paper after 5 minutes of incubation and the grid was air dried for 10 minutes. Samples were observed using a Tecnai G20 TWIN Transmission Electron Microscope (FEI, USA), imaged, and analyzed at $200 \mathrm{kV}$.

\section{Western blot analysis}

LNCaP cells were harvested and suspended in radioimmunoprecipitation assay (RIPA) buffer containing the protease inhibitor cocktail. BCA Protein Assay Kit (Beyotime, China) was used to quantify protein concentrations. Then cell lysates and exosomes were loaded onto the SDS-PAGE gel. The electrophoresed proteins were transferred to PVDF membranes (Millipore, USA). Membranes were blocked in 5\% nonfat milk, followed by overnight incubation with diluted CD63 and TSG101 antibodies (1:1, 000; Proteintech Group, Chicago, IL, USA). Membranes were washed and probed with a horseradish peroxidase-conjugated secondary antibody (1:5, 000; Santa Cruz Biotechnology, Inc., Santa Cruz, CA, USA).

\section{Dynamic light scattering analysis}

Dynamic light scattering (DLS) analysis was applied to measure the size of exosomes using the Zetasizer Nano ZS90 instrument (Malvern, UK). Exosome samples diluted in PBS were analyzed in an equilibration time of 70 seconds at a constant temperature of $25^{\circ} \mathrm{C}$. Samples were calibrated by CPC100 standard particles diluted 1, 000-fold under identical settings.

Isolation of tumor-derived exosomes by dual-antibody-functionalized immunoaffinity system.

Dynabeads ${ }^{\mathrm{TM}} \mathrm{M}-280$ Streptavidin magnetic beads (Life technologies AS, Oslo, Norway) were conjugated with biotin anti-human EpCAM antibody (R\&D Systems, Minneapolis, MN, USA) and biotin anti-human PSMA antibody (BioLegend, San Diego, CA, USA), according to the protocols supplied by manufacturers. Total exosomes (from $400 \mu \mathrm{l}$ plasma or three $75 \mathrm{~cm}^{2}$ flasks) were incubated with conjugated-magnetic beads $(20 \mu \mathrm{l})$ at $4^{\circ} \mathrm{C}$ for 16 hours. The beads were washed with PBS three times then suspended either in RIPA buffer containing the protease inhibitor cocktail or in RNAiso Blood (TaKaRa, Tokyo, Japan), and were stored at $-20^{\circ} \mathrm{C}$ until use.

\section{Quantitative real-time PCR}

Total RNA from total exosomes and tumor-derived exosomes was extracted using RNAiso Blood (TaKaRa, Tokyo, Japan) following the manufacturer's instructions, and then dissolved in $10 \mu \mathrm{l}$ diethylpyrocarbonate-treated water. The quality of RNA was assessed by a Thermo Scientific ${ }^{\mathrm{TM}}$ Nanodrop 2000 platform (Thermo Fisher Scientific, Waltham, MA, USA). Finally, the extracted RNA was used to synthesize cDNA using ReverTra Ace- $\alpha$ First-strand cDNA Synthesis Kit (Toyobo, Osaka, Japan). The levels of IncRNAs were assessed on the StepOnePlus ${ }^{\text {TM }}$ Real-time PCR System (Applied Biosystems, Foster City, CA, USA) using SYBRß Green Realtime PCR Master Mix (Toyobo, Osaka, Japan) according to the manufacturer's instructions. The internal control was GAPDH [37], and its primer sequences were as follows: forward primer, 5'-AGACTTGTCCAACCACTAGAACT-3'; reverse primer, 5'-AGGGCTGAGGGCTGATTC-3'. The sequences of primers for SChLAP1 were as follows: forward primer, $5^{\prime}$-TGGACACAATTTCAAGTCCTCA-3'; reverse primer, $5^{\prime}$-CATGGTGAAAGTGCCTTATACA- $3^{\prime}$. The sequences of primers for SAP30L-AS1 were as follows: forward primer, 5'-TGAATGGGCTCACCTGTTCC-3'; reverse primer, 5'-AGGTCCGGAAGGGAGACTTT- ${ }^{\prime}$. The reactions started at $95^{\circ} \mathrm{C}$ for $1 \mathrm{~min}$, followed by 40 cycles of $95^{\circ} \mathrm{C}$ for 15 seconds, $60^{\circ} \mathrm{C}$ for 20 seconds and $72^{\circ} \mathrm{C}$ for 45 seconds. The levels of IncRNAs were determined by the $2^{-\Delta \Delta c t}$ method. All experiments were carried out twice with negative control.

\section{Statistical analysis}

Data were analyzed by GraphPad Prism V.5.00 software (GraphPad Software, San Diego CA, USA) and SPSS 15.0 (SPSS, Inc., Chicago, IL, USA). One-way analysis of variance (ANOVA) was used to investigate the differences between groups. ROC curve was applied to evaluate the diagnostic value. Differences between 


\section{Cellular Physiology Cell Physiol Biochem 2018;46:532-545 and Biochemistry Published online: April 03, $2018 \quad \begin{aligned} & \text { DOI: 10.1159/000488620 } 2018 \text { The Author(s). Published by S. Karger AG, Basel } \\ & \text { www.karger.com/cpb }\end{aligned}$

two samples were compared using Student's $t$-test. $P$ values $<0.05$ were considered statistically significant.

\section{Results}

Isolation characterization exosomes from cell culture supernatant using dualantibody-functionalized immunoaffinity system

Exosomes were first isolated from conditioned cell culture medium using a commercial kit. TEM pictures showed that the vesicle size of isolated exosomes ranged from 30 to $120 \mathrm{~nm}$ in diameter (Fig. 1A). The presence of exosomal marker protein CD63 was then analyzed by western blotting (Fig. 1B). Exosomal marker protein CD63 was enriched in exosome fractions as compared to cell lysates (Fig. 1B). To further enrich prostate tumor-derived exosomes, an immunoaffinity system was developed using magnetic beads conjugated with both anti-EpCAM and anti-PSMA antibodies based on our previous related researches (Fig. 1C). To validate our isolation procedure, CD63 was probed on the samples from different fractions of the isolation process by western blotting. As shown in Fig. 1D, the expression of CD63 for a certain number of total exosomes was pictured in the lane 1. Then, the magnetic beads conjugated with anti-EpCAM and anti-PSMA antibody could effectively capture exosomes in equal amounts of total exosomes (lane 2 of Fig. 1D), whereas there were significantly fewer exosomes in magnetic beads unbound fraction (lane 3 of Fig. 1D). To test whether magnetic beads could nonspecifically bind to exosomes, unconjugated magnetic beads were incubated with exosomes, and it was found that magnetic beads alone had minimal capacity to bind to exosomes (lane 4 of Fig. 1D), while most exosomes were present in the unbound fraction (lane 5 of Fig. 1D). Thus, the exosomes captured by conjugated magnetic beads were most likely to bind to dual-antibody as opposed to magnetic beads. Based on recent literature and previous work in our laboratory (research in the molecular profiling of pooled circulating tumor cells from PCa patients using dual-antibody-functionalized microfluidic device), it was decided to detect two lncRNAs in tumor-derived exosomes and validate them in the TCGA database (see online suppl. material, Fig. S1). The two IncRNAs were SChLAP1 and SAP30L-AS1, which were closely related to PCa. Expression of the two lncRNAs in tumor-derived exosomes was significantly higher than that in total exosomes, which indicated that these lncRNAs were enriched in tumorderived exosomes (Fig. 1E) and might be potential biomarkers for PCa. 


\section{Cellular Physiology Cell Physiol Biochem 2018;46:532-545 and Biochemistry Published online: April 03, $2018 \quad \begin{aligned} & \text { DOI: } 2018 \text { The Author(s). Published by S. Karger AG, Basel } \\ & \text { www.karger.com/cpb }\end{aligned}$ \\ Wang et al.: Diagnostic Potential of Tumor-Derived Exosomal LncRNAs in PCa}

Fig. 2. Isolation and characterization of tumor-dervied exosomes from plasma with EpCAM and PSMA beads. (A) TEM characterization of total exosomes from plasma; the histogram shows the diameter of exosomes from plasma at $80 \mathrm{~nm}$ on the right (scale $=200 \mathrm{~nm}$ ). (B) Protein lysates obtained from total exosomes were assayed using antibodies against exosomal markers CD63 and TSG101. (C) DLS analysis shows representative size distribution of exosomes. (D) Western blot analysis for tumor-derived exosomes from patients and healthy controls. Almost no exosomes were captured by EpCAM and PSMA beads from the healthy controls. (E) RT-qPCR data

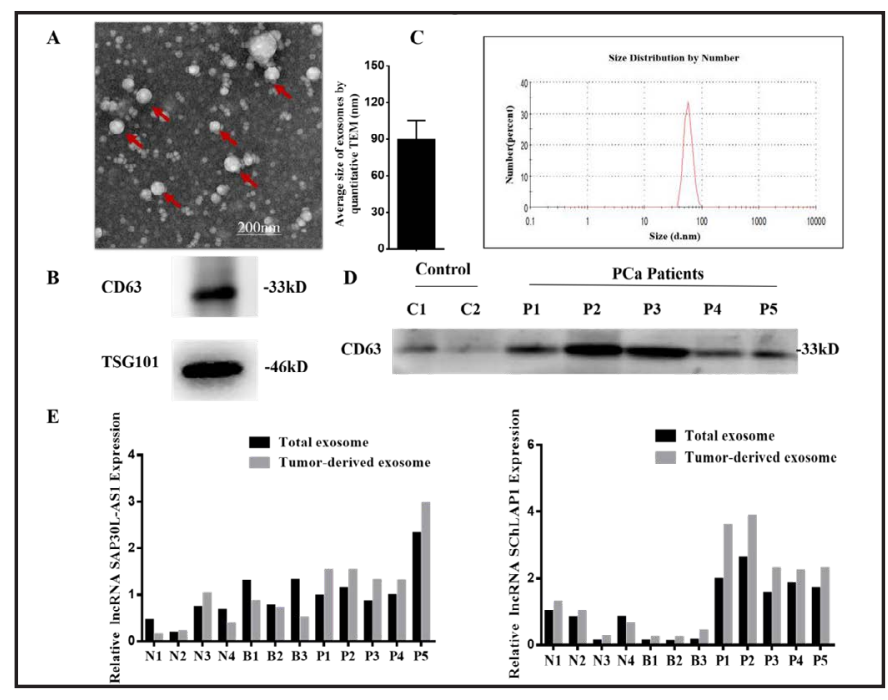
on two IncRNA expression levels for to-

tal exosomes and tumor-derived exosomes from patients with PCa, patients with BPH and healthy individuals. The contents of the two lncRNAs in tumor-derived exosomes is higher than that in total exosomes.

\section{Capture and identification \\ of tumor-derived exosomes from PCa patients' plasma \\ To further test our cap-} ture system in human patients, exosomes from plasma were first isolated and shown to be round-shaped (Fig. 2A, TEM picture on left) with average diameter of $80 \mathrm{~nm}$ (Fig. 2A, summary of histogram on right). Particular exosomal marker proteins, CD63 and TSG101, were further used to confirm the identity of the isolated vesicles (Fig. 2B). Furthermore, DLS were applied to total exosomes isolated from plasma samples to verify the size of exosomes and their size distribution. A typical distribution of the hydrodynamic radius of the exosomes obtained from DLS measurements is shown in Fig. 2C. Magnetic beads conjugated with antiEpCAM and anti-PSMA antibodies were then investigated to determine whether they were capable of capturing tumor-derived exosomes from plasma. For this purpose, total exosomes were isolated from the plasma $(400 \mu \mathrm{l})$ of healthy controls and PCa patients by a commercial kit, and these total exosomes were then incubated with EpCAM and PSMA magnetic beads to further enrich tumor-derived exosomes. As shown in Fig. 2D, C1 and C2 are healthy individuals, and P1 to P5 are PCa patients. PCa patients exhibited higher expression of CD63 in isolated exosomes than the healthy controls, suggesting that magnetic beads conjugated with anti-EpCAM and anti-PSMA antibodies have higher affinity for exosomes derived from PCa patients' plasma. To further test the specificity of our dual-antibody immunoaffinity system, 
three patients with BPH were included in our test, then real-time RT-PCR was employed to quantify expression of SChLAP1 and SAP30L-AS1 in total exosomes and immunecaptured exosomes. Consistent with our observation on exosomes derived from cancer cell lines, it was found that, firstly, these two IncRNAs were upregulated in total exosomes derived from PCa patients as compared to that in either normal individuals or patients with BPH; and, secondly, our dual-antibody immunoaffinity system further enriched two IncRNAs in tumor-derived exosomes from total exosomes from PCa plasma, although this was not the case for exosomes from either normal individuals or patients with BPH (Fig. 2E). Taken together, our results suggest that our dualantibody immunoaffinity system can effectively enrich tumor-derived exosomes for further analysis.

\section{The expression levels of SAP3OL-AS1 and SChLAP1 in tumor-derived exosomes}

After the establishment of our capture approach, experiments were performed with a larger cohort of plasma samples to compare the exosomal SChLAP1 and SAP30L-AS1 levels among PCa patients, BPH patients and healthy volunteers by RT-qPCR. The RNA was extracted from tumor-derived exosomes of PCa patients and total exosomes of patients with BPH and healthy volunteers. It was found that the SAP30L-AS1 level in BPH patients was significantly higher than that in controls and PCa patients (controls vs. BPH, $P<0.0001$; BPH vs. PCa, $P<0.05$; Fig. 3A). Interestingly, expression of SChLAP1 was significantly downregulated in BPH patients when compared to the level in controls and PCa patients $(P<0.0001$; Fig. 3B). Meanwhile, the SChLAP1 level in PCa patients was significantly upregulated compared to the level in healthy individuals $(P<0.0001 ; \mathrm{Fig} .3 \mathrm{~B})$. Thus, our results suggest that it might be useful to quantify exosomal lncRNA levels to diagnose BPH and PCa.

The association of expression of IncRNAs in tumor-derived exosomes with patients' clinicopathological parameters

To further test the clinical application of the level of lncRNAs in tumor-derived exosomes, the relationship between exosomal lncRNAs and clinicopathological parameters 
Fig. 5. ROC curves for PCa. (A and B) The area under the ROC curve indicated that SAP30LAS1 and SChLAP1 had adequate diagnostic value for differentiating PCa patients from controls. (C) The area of the combination of two IncRNA was equal to 0.92. (D and E) Two IncRNAs separately combined with PSA possessed a moderate ability for discrimination. (F). The area under the curve for two lncRNAs combined with PSA was 0.888.

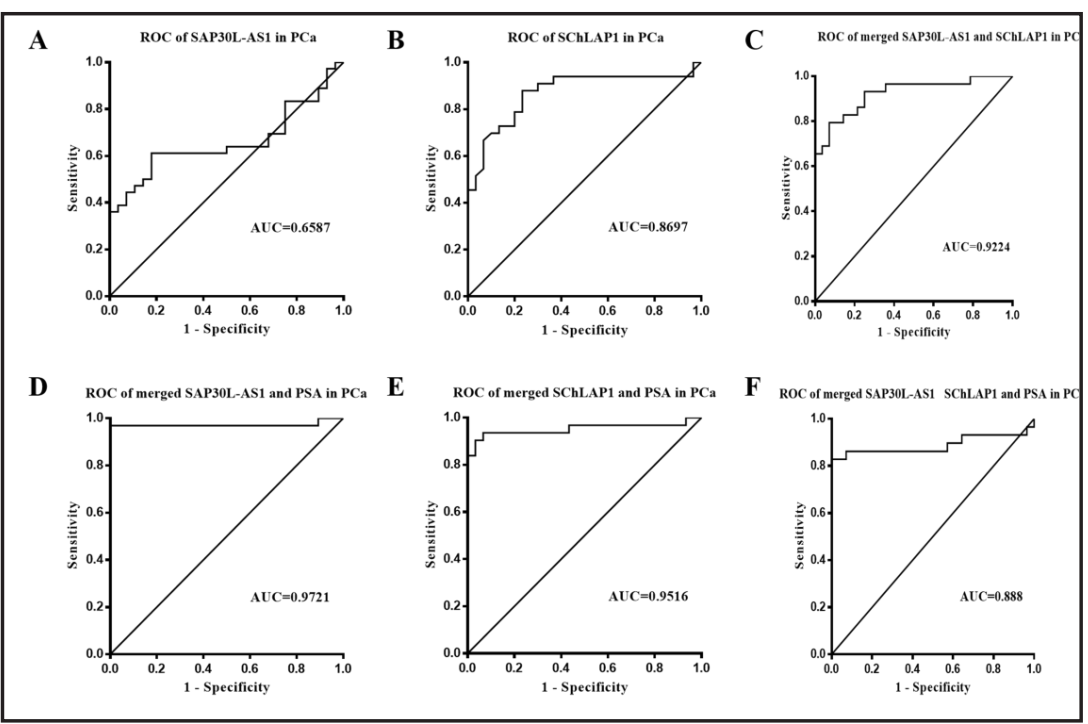

Table 2. AUC of the expression of SAP30L-AS1 and SChLAP1 in all subgroups. AUC, area under the curve; 95\% CI, 95\% confidence intervals; Se, sensitivity; Sp, specificity

\begin{tabular}{|c|c|c|c|c|c|c|c|c|c|c|}
\hline \multirow[b]{2}{*}{ Group } & \multicolumn{5}{|c|}{ BPH vs controls } & \multicolumn{5}{|c|}{ PCa vs controls } \\
\hline & AUC & $95 \% \mathrm{CI}$ & $P$ value & $\begin{array}{l}\mathrm{Se} \\
(\%)\end{array}$ & $\begin{array}{l}\text { Sp } \\
(\%)\end{array}$ & AUC & $95 \% \mathrm{CI}$ & $P$ value & $\begin{array}{l}\mathrm{Se} \\
(\%)\end{array}$ & $\begin{array}{l}\mathrm{Sp} \\
(\%)\end{array}$ \\
\hline SAP30L-AS1 & 0.7806 & $\begin{array}{c}0.669- \\
0.892\end{array}$ & $<0.0001$ & 66.7 & 92.9 & 0.6587 & $\begin{array}{c}0.522- \\
0.795\end{array}$ & $<0.0001$ & 61.1 & 82.1 \\
\hline SChLAP1 & 0.908 & $\begin{array}{l}0.835- \\
0.980\end{array}$ & $<0.0001$ & 87.0 & 96.7 & 0.8697 & $\begin{array}{l}0.776- \\
0.963\end{array}$ & $<0.0001$ & 87.9 & 76.7 \\
\hline SAP30L-AS1 and SChLAP1 & 0.935 & $\begin{array}{l}0.870- \\
0.999\end{array}$ & $<0.0001$ & 90.5 & 96.4 & 0.9224 & $\begin{array}{l}0.852- \\
0.992\end{array}$ & $<0.0001$ & 79.3 & 92.9 \\
\hline SAP30L-AS1 and PSA & 0.919 & $\begin{array}{c}0.849- \\
0.989\end{array}$ & $<0.0001$ & 85.4 & 99.0 & 0.972 & $\begin{array}{c}0.918- \\
0.999\end{array}$ & $<0.0001$ & 96.9 & 99.0 \\
\hline SChLAP1 and PSA & 0.981 & $\begin{array}{c}0.956- \\
0.999\end{array}$ & $<0.0001$ & 99.0 & 90.0 & 0.952 & $\begin{array}{c}0.887- \\
0.999\end{array}$ & $<0.0001$ & 90.3 & 96.7 \\
\hline $\begin{array}{l}\text { SAP30L-AS1 and SChLAP1 } \\
\text { and PSA }\end{array}$ & 0.986 & $\begin{array}{c}0.966- \\
0.999\end{array}$ & $<0.0001$ & 92.7 & 96.4 & 0.888 & $\begin{array}{c}0.784- \\
0.992 \\
\end{array}$ & $<0.0001$ & 82.8 & 99.0 \\
\hline
\end{tabular}

in PCa patients was analyzed. As shown in Table 1, there was no relationship between the expression of these lncRNAs levels of PCa patients and clinicopathological features including age, lymphatic metastasis and development of metastasis. However, SAP30L-AS1 level was found to be related to PSA values and tumor invasion (Fig. 4A and B). Furthermore, SChLAP1 expression was significantly higher in PCa patients with higher Gleason scores (Fig. 4C).

Utility of tumor-derived exosomal SAP3OL-AS1 and SChLAP1 diagnostic prediction for PCa

We constructed ROC curves to estimate the diagnostic value of exosomal SAP30L-AS1 and SChLAP1, so as to assess their potential for clinical application. The integration of the area under the ROC curve indicated that SAP30L-AS1 and SChLAP1 had adequate diagnostic value for differentiating PCa patients from the controls (Fig. 5, A and B). The area of the combination of two lncRNAs was equal to 0.92 , but the sensitivity was not as good as for SChLAP1 solely (Fig. 5C and Table 2). In order to further investigate the potential value of exosomal lncRNAs as clinical biomarkers for diagnosing PCa, two lncRNAs separately combined with PSA were possessed of a moderate ability for discriminating between PCa patients and controls (Fig. 5, D and E). However, the diagnostic value of two lncRNAs combined with PSA was not obvious (Fig. 5F and Table 2). Meanwhile, exosomal SAP30L-AS1 and SChLAP1 were also found to have significant diagnostic value for BPH (see online suppl. material, Fig. S2 and Table 2). 
Fig. 6. Tumor-derived exosomal lncRNAs detect $\mathrm{PCa}$ in patients with PSA levels of 4-10 ng/ ml. (A and B) SChLAP1 was effective for differentiating between BPH and PCa when the concentration of PSA was 4-10ng/ml. (C) The ROC curves for the expres-

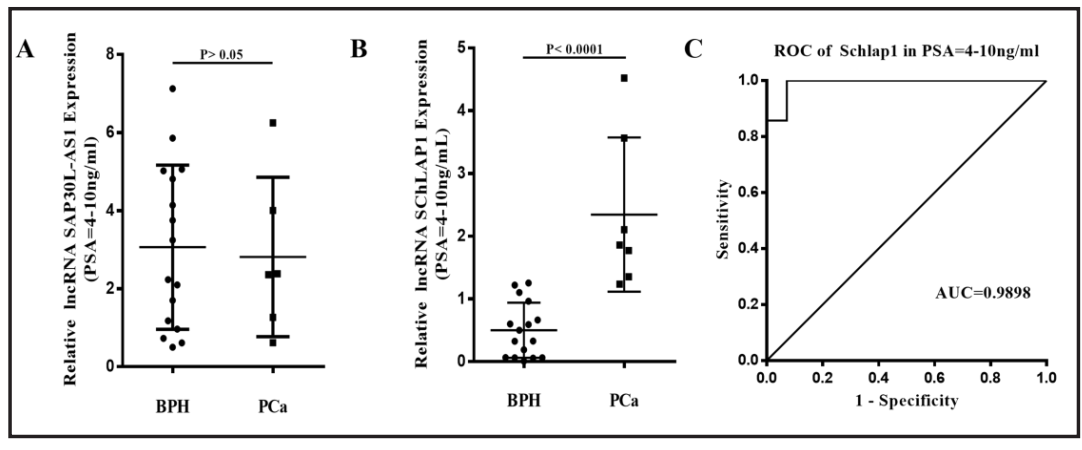
sion of SChLAP1 for PCa vs. $\mathrm{BPH}$ in the PSA gray zone.

Tumor-derived exosomal SChLAP1 detects PCa in patients with PSA levels of 4-10 ng/ml

When the concentration of PSA was $4-10 \mathrm{ng} / \mathrm{ml}$ which was defined as the gray zone, the PSA test had low specificity. In present research, SAP30L-AS1 and SChLAP1 were investigated to determine whether they could be effective in differentiating between BPH and PCa in the PSA gray zone (Fig. 6, A and B). Interestingly, the expression of tumor-derived exosomal SChLAP1 in PCa was higher than that in total exosomes from patients with BPH (Fig. 6B). Therefore, exosomal SChLAP1 was promising in terms of helping doctors to make the diagnosis as to whether a patient with a PSA level in the gray zone had PCa, which could help to reduce unnecessary biopsies. To further evaluate the ability of exosomal SChLAP1 expression in plasma to discriminate between BPH and PCa in patients with a PSA level of 4-10 ng/ml, the ROC curves were plotted in Fig. 6C. The area under the ROC curve is 0.9898 .

\section{Discussion}

Researchers have found that circulating exosomes in plasma contain a group of proteomic and genetic signatures in various diseases, especially cancer, thus presenting an enormous opportunity in terms of cancer diagnosis [38]. However, this is technically challenging due to the lack of an effective method for enriching tumor-derived exosomes from total exosomes. Therefore, obtaining high purity exosomes is necessary before further exploration of their functional mechanism and composition. A plethora of purification approaches for exosome isolation have been reported, including ultracentrifugation, filtration, chemical precipitation, affinity-binding beads and microfluidics techniques [39, 40]. Sequential centrifugation followed by ultracentrifugation is the most common approach used to isolate total exosomes [41]. However, this method is time consuming and demanding in terms of instrumentation [39]. Immunocapture using tumor-specific proteins on exosome surface antibodies (e.g., anti-HER2/neu or PSMA) is another optimized method which has emerged as a viable choice for exosome purification [38, 42].

In the present study, a immunocapture method was developed using magnetic beads conjugated with anti-EpCAM and anti-PSMA antibodies to isolate prostate tumor-derived exosomes from plasma (Fig. 7). An exosome precipitation reagent was used, followed by immunoaffinity isolation to purify prostate tumor-derived exosomes, a process which is relatively quick and easy. Furthermore, tumor-derived exosomes might reflect both the individual characteristics of patients and adequate representative messages to diagnose prostate tumor [43]. In the current study, tumor-derived exosomes were characterized in cell culture medium and in clinical samples from PCa patients. Our results show that the dual-antibody capture system can effectively capture tumor-derived exosomes from total exosomes. EpCAM and PSMA are marker proteins that are frequently overexpressed in PCa exosomes $[30,44]$. EpCAM is a ubiquitous cancer marker expressed exclusively in epithelial cells and epithelium-originated tumors, and it has been used as a specific antibody to isolate 


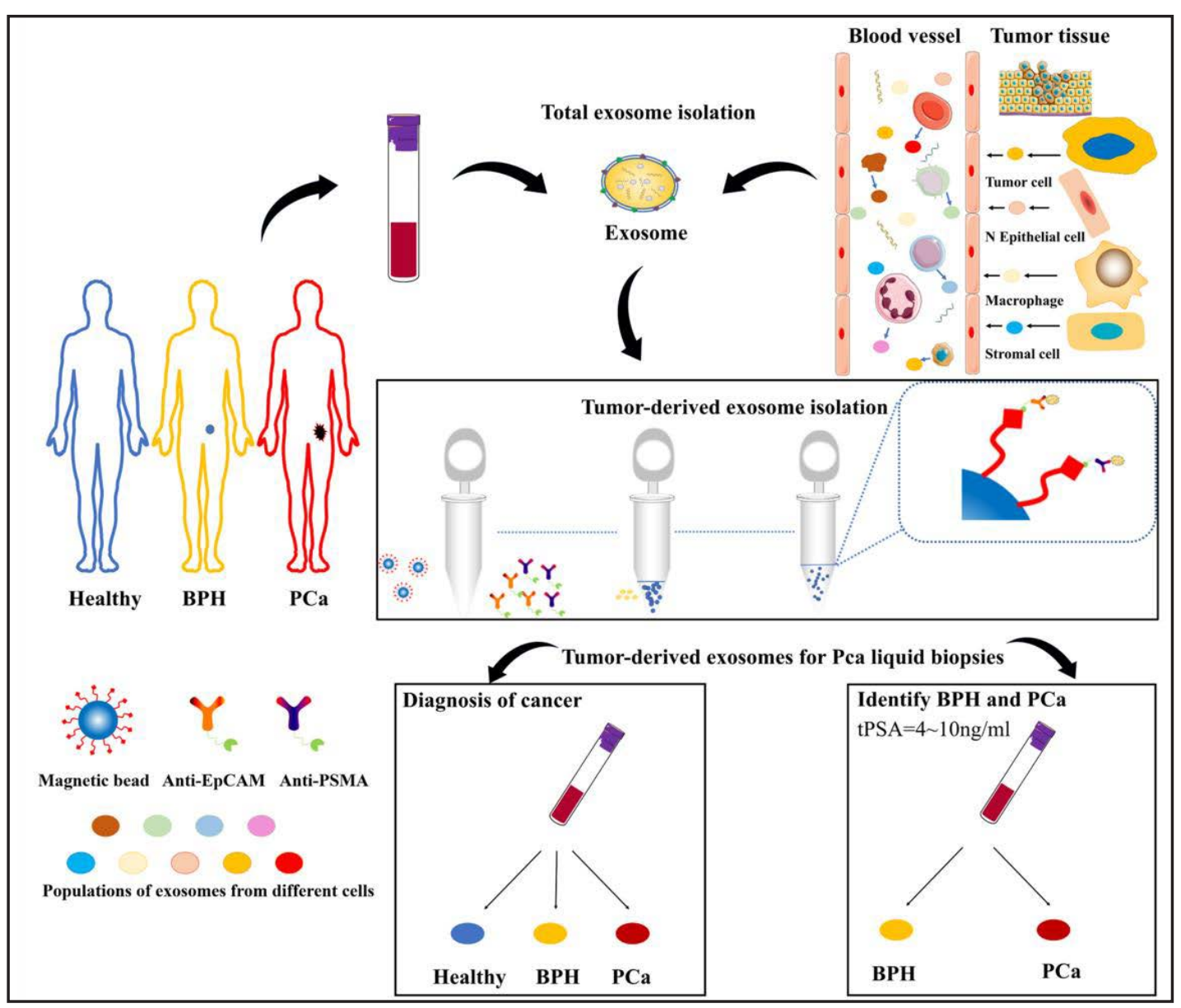

Fig. 7. Methods used to purify exosomes and assess the diagnostic value of exosomal lncRNAs.

tumor-derived exosomes to avoid the interference of exosomes from nonepithelial tissues $[44,45]$. PSMA is generally regarded as a biomarker enriched in exosomes from PCa cells, and its levels were significantly increased in plasma-derived exosomes from PCa patients compared with healthy individuals [30, 40]. Recent studies suggest that the expression level of PSMA is even higher than EpCAM in exosomes from PCa cell lines [40]. Thus, the dualantibody capture system is superior to the single EpCAM system. In our study, it was found that conjugation of anti-EpCAM and anti-PSMA antibodies to magnetic beads was effective for enriching exosomes specifically from PCa patients as compared to healthy individuals. More importantly, further studies were designed to test whether lncRNAs in purified tumorderived exosomes could serve as potential biomarkers for PCa diagnosis.

Liquid biopsy is a blood test that encompasses the analysis of circulating tumor cells, circulating tumor DNA and exosomes derived from cancer cells $[46,47]$. So far, every cell that has been studied secretes exosomes. Previous studies have demonstrated that tumor-derived exosomes had higher content of miRNA and IncRNA [18, 32, 48, 49]. It was the first of these studies that indicated that exosomes could transport mRNA, miRNA and angiogenic proteins leading to tumor growth and providing blood-based diagnostic information [47]. More recent researches efforts have demonstrated that tumor-derived exosomes have potential for use as noninvasive diagnostic biomarkers, as opposed to traditional tissue biopsy [24, $32,40,48]$. The detection of tumor-derived exosomal lncRNAs has some obvious advantages. First, the collection of peripheral blood to obtain exosomes is easily available and minimally invasive. Second, blood samples could be taken at any time during treatment to achieve realtime and dynamic monitoring of molecular changes in disease and in tumors. Finally, the

\section{KARGER}




\section{Cellular Physiology Cell Physiol Biochem 2018;46:532-545 \\ \begin{tabular}{ll|l} 
and Biochemistry Published online: April 03, 2018 & $\begin{array}{l}\text { (c) } 2018 \text { The Author(s). Published by S. Karger AG, Basel } \\
\text { www.karger.com/cpb }\end{array}$ \\
\hline
\end{tabular} \\ Wang et al.: Diagnostic Potential of Tumor-Derived Exosomal LncRNAs in PCa}

accuracy of tumor detection could be improved by analyzing tumor-derived exosomes to detect tumors which are not yet apparent.

After establishing the capture system of prostate tumor-derived exosomes, a diagnostic analysis of tumor-derived exosomal lncRNAs was constructed. LncRNA SChLAP1 is an emerging molecule which is an important mediator for tumor invasion and hematogenous metastasis. SChLAP1 levels can independently predict tumor metastasis and PCa specific mortality [11]. In our study, SChLAP1 could effectively discriminate PCa patients from individuals with $\mathrm{BPH}$, as well as healthy controls. The Gleason score is one of the most commonly used pathological parameters to assess the aggressiveness of PCa. SChLAP1 was significantly higher in PCa patients with higher Gleason scores, consistent with previous studies [50]. However, the Gleason score for prostate biopsy sometimes differs from the Gleason score after radical prostatectomy [51]. The present results also indicate that expression of SChLAP1 correlates with Gleason score. SChLAP1 may therefore be a favorable biomarker for assessing various treatment options for patients with PCa. Another lncRNA, SAP30L-AS1, was one of the lncRNAs existing in exosomes isolated from four PCa cell lines [18]. The current study is the first study to investigate the expression of SAP30L-AS1. The SAP30L-AS1 level in BPH patients was significantly higher than that in controls and PCa patients. In addition, SAP30L-AS1 level was positively correlated with PSA levels and tumor invasion in our clinical analysis. However, the exact mechanism requires further research.

As is well known, the PSA test is the most common method for PCa screening. Nevertheless, the PSA test has a limitation in that the specificity decreases drastically when PSA levels are in the gray zone [5]. Therefore, there is an unmet medical need to find a non-invasive diagnostic biomarker which can distinguish the low- and high-risk patients for clinical decision making. As an emerging technology, the SERS diagnostic approach has shown great potential for differentiating between PCa and BPH patients who had a PSA level in the gray zone, through analyzing the biochemical constituents in serum [52]. However, the technology is unwieldy and inappropriate for most clinical settings. Exosomal lncRNA-p21 levels were also proven to distinguish PCa from BPH [34]. In our study, the expression of tumor-derived exosomal SChLAP1 in PCa was higher than that in total exosomes from BPH patients. Exosomal SChLAP1 showed promise for helping doctors to make the diagnosis, and it could potentially reduce unnecessary biopsies. Also, the diagnostic performance of SChLAP1 in tumor-derived exosomes is perfect, with an area under the ROC curve of 0.9898. The integration of the area under the ROC curve indicated that both SAP30L-AS1 and SChLAP1 had adequate diagnostic value for PCa and BPH. Further analysis showed that the combination of two lncRNAs and PSA achieved a better diagnostic accuracy. Thus, SChLAP1 and SAP30L-AS1 may represent a promising target for PCa diagnosis.

It is worth noting that our study was limited by small clinical samples. As a future direction, different groups of patients with therapies and CRPC will be compared in order to study the correlation of EpCAM/PSMA levels with the progression of cancer.

In conclusion, our study demonstrates for the first time that the detection of tumorderived exosomal lncRNAs in plasma may lead to the identification of biomarkers with potential diagnostic applications in PCa. SAP30L-AS1 and SChLAP1 are promising markers which show with potential for the detection and stratification of PCa. Further analysis is still essential to test the exact molecular mechanisms of SAP30L-AS1 and SChLAP1 in the regulation of $\mathrm{PCa}$.

\section{Acknowledgements}

This work was supported by Applied Basic Research Program of Science and Technology Bureau Foundation of Wuhan (No. 2016060101010054) and National Natural Science Foundation of China (grant No. 81672114). This work was also funded by Science and Technology Innovation Fostering Foundation of Zhongnan Hospital of Wuhan University (cxpy20160025) and Wuhan City health and family planning medical talented youth development project. 


\section{Cellular Physiology Cell Physiol Biochem 2018;46:532-545 \begin{tabular}{ll|l} 
and Biochemistry & Dublished online: April 03, 2018 & $\begin{array}{l}\text { C } 2018 \text { The Author(s). Published by S. Karger AG, Basel } \\
\text { www.karger.com/cpb }\end{array}$
\end{tabular} \\ Wang et al.: Diagnostic Potential of Tumor-Derived Exosomal LncRNAs in PCa}

\section{Disclosure Statement}

The authors report no conflicts of interest in this work.

\section{References}

1 Siegel RL, Miller KD, Jemal A: Cancer statistics, 2016. CA Cancer J Clin 2016;66:7-30.

2 Torre LA, Bray F, Siegel RL, Ferlay J, Lortet-Tieulent J, Jemal A: Global cancer statistics, 2012. CA Cancer J Clin 2015;65:87-108.

3 Ren S, Peng Z, Mao JH, Yu Y, Yin C, Gao X, Cui Z, Zhang J, Yi K, Xu W, Chen C, Wang F, Guo X, Lu J, Yang J, Wei M, Tian Z, Guan Y, Tang L, Xu C, Wang L, Gao X, Tian W, Wang J, Yang H, Wang J, Sun Y: RNA-seq analysis of prostate cancer in the Chinese population identifies recurrent gene fusions, cancer-associated long noncoding RNAs and aberrant alternative splicings. Cell Res 2012;22:806-821.

4 Yuan X, Cai C, Chen S, Chen S, Yu Z, Balk SP: Androgen receptor functions in castration-resistant prostate cancer and mechanisms of resistance to new agents targeting the androgen axis. Oncogene 2014;33:28152825.

5 Hayes JH, Barry MJ: Screening for prostate cancer with the prostate-specific antigen test: a review of current evidence. Jama 2014;311:1143-1149.

6 Guttman M, Donaghey J, Carey BW, Garber M, Grenier JK, Munson G, Young G, Lucas AB, Ach R, Bruhn L, Yang X, Amit I, Meissner A, Regev A, Rinn JL, Root DE, Lander ES: lincRNAs act in the circuitry controlling pluripotency and differentiation. Nature 2011;477:295-300.

7 Prensner JR, Chinnaiyan AM: The emergence of lncRNAs in cancer biology. Cancer Discov 2011;1:391-407.

8 Luo G, Wang M, Wu X, Tao D, Xiao X, Wang L, Min F, Zeng F, Jiang G: Long Non-Coding RNA MEG3 Inhibits Cell Proliferation and Induces Apoptosis in Prostate Cancer. Cell Physiol Biochem 2015;37:2209-2220.

-9 Prensner JR, Iyer MK, Balbin OA, Dhanasekaran SM, Cao Q, Brenner JC, Laxman B, Asangani IA, Grasso CS, Kominsky HD, Cao X, Jing X, Wang X, Siddiqui J, Wei JT, Robinson D, Iyer HK, Palanisamy N, Maher CA, Chinnaiyan AM: Transcriptome sequencing across a prostate cancer cohort identifies PCAT-1, an unannotated lincRNA implicated in disease progression. Nat Biotechnol 2011;29:742-749.

10 Bussemakers MJ, van Bokhoven A, Verhaegh GW, Smit FP, Karthaus HF, Schalken JA, Debruyne FM, Ru N, Isaacs WB: DD3: a new prostate-specific gene, highly overexpressed in prostate cancer. Cancer Res 1999;59:5975-5979.

-11 Prensner JR, Iyer MK, Sahu A, Asangani IA, Cao Q Patel L, Vergara IA, Davicioni E, Erho N, Ghadessi M, Jenkins RB, Triche TJ, Malik R, Bedenis R, McGregor N, Ma T, Chen W, Han S, Jing X, Cao X, Wang X, Chandler B, Yan W, Siddiqui J, Kunju LP, Dhanasekaran SM, Pienta KJ, Feng FY, Chinnaiyan AM: The long noncoding RNA SChLAP1 promotes aggressive prostate cancer and antagonizes the SWI/SNF complex. Nat Genet 2013;45:1392-1398.

12 Mehra R, Shi Y, Udager AM, Prensner JR, Sahu A, Iyer MK, Siddiqui J, Cao X, Wei J, Jiang H, Feng FY, Chinnaiyan AM: A novel RNA in situ hybridization assay for the long noncoding RNA SChLAP1 predicts poor clinical outcome after radical prostatectomy in clinically localized prostate cancer. Neoplasia 2014;16:1121-1127.

13 Zhang W, Ren SC, Shi XL, Liu YW, Zhu YS, Jing TL, Wang FB, Chen R, Xu CL, Wang HQ Wang HF, Wang Y, Liu B, Li YM, Fang ZY, Guo F, Lu X, Shen D, Gao X, Hou JG, Sun YH: A novel urinary long non-coding RNA transcript improves diagnostic accuracy in patients undergoing prostate biopsy. Prostate 2015;75:653661.

14 Shukla S, Zhang X, Niknafs YS, Xiao L, Mehra R, Cieslik M, Ross A, Schaeffer E, Malik B, Guo S, Freier SM, Bui HH, Siddiqui J, Jing X, Cao X, Dhanasekaran SM, Feng FY, Chinnaiyan AM, Malik R: Identification and Validation of PCAT14 as Prognostic Biomarker in Prostate Cancer. Neoplasia 2016;18:489-499.

15 Prensner JR, Zhao S, Erho N, Schipper M, Iyer MK, Dhanasekaran SM, Magi-Galluzzi C, Mehra R, Sahu A, Siddiqui J, Davicioni E, Den RB, Dicker AP, Karnes RJ, Wei JT, Klein EA, Jenkins RB, Chinnaiyan AM, Feng FY: RNA biomarkers associated with metastatic progression in prostate cancer: a multi-institutional highthroughput analysis of SChLAP1. The Lancet Oncology 2014;15:1469-1480.

16 Gallo A, Tandon M, Alevizos I, Illei GG: The majority of microRNAs detectable in serum and saliva is concentrated in exosomes. PLoS One 2012;7:e30679. 


\section{Cellular Physiology Cell Physiol Biochem 2018;46:532-545 \begin{tabular}{l|l} 
and Biochemistry Published online: April 03, 2018 & $\begin{array}{l}\text { D) } 2018 \text { The Author(s). Published by S. Karger AG, Basel } \\
\text { www.karger.com/cpb }\end{array}$
\end{tabular} \\ Wang et al.: Diagnostic Potential of Tumor-Derived Exosomal LncRNAs in PCa}

17 Li XJ, Ren ZJ, Tang JH, Yu Q: Exosomal MicroRNA MiR-1246 Promotes Cell Proliferation, Invasion and Drug Resistance by Targeting CCNG2 in Breast Cancer. Cell Physiol Biochem 2017;44:1741-1748.

18 Ahadi A, Brennan S, Kennedy PJ, Hutvagner G, Tran N: Long non-coding RNAs harboring miRNA seed regions are enriched in prostate cancer exosomes. Sci Rep 2016;6:24922.

19 Caby MP, Lankar D, Vincendeau-Scherrer C, Raposo G, Bonnerot C: Exosomal-like vesicles are present in human blood plasma. Int Immunol 2005;17:879-887.

20 Stoorvogel W, Kleijmeer MJ, Geuze HJ, Raposo G: The biogenesis and functions of exosomes. Traffic 2002;3:321-330.

-21 Thery C, Zitvogel L, Amigorena S: Exosomes: composition, biogenesis and function. Nat Rev Immunol 2002;2:569-579.

-22 Thery C: Exosomes: secreted vesicles and intercellular communications. F1000 Biol Rep 2011;3:15.

-23 Pisitkun T, Shen RF, Knepper MA: Identification and proteomic profiling of exosomes in human urine. Proc Natl Acad Sci U S A 2004;101:13368-13373.

24 Michael A, Bajracharya SD, Yuen PS, Zhou H, Star RA, Illei GG, Alevizos I: Exosomes from human saliva as a source of microRNA biomarkers. Oral Dis 2010;16:34-38.

-25 Admyre C, Johansson SM, Qazi KR, Filen JJ, Lahesmaa R, Norman M, Neve EP, Scheynius A, Gabrielsson S: Exosomes with immune modulatory features are present in human breast milk. J Immunol 2007;179:19691978.

-26 Admyre C, Grunewald J, Thyberg J, Gripenback S, Tornling G, Eklund A, Scheynius A, Gabrielsson S: Exosomes with major histocompatibility complex class II and co-stimulatory molecules are present in human BAL fluid. Eur Respir J 2003;22:578-583.

27 Tan M, Yan HB, Li JN, Li WK, Fu YY, Chen W, Zhou Z: Thrombin Stimulated Platelet-Derived Exosomes Inhibit Platelet-Derived Growth Factor Receptor-Beta Expression in Vascular Smooth Muscle Cells. Cell Physiol Biochem 2016;38:2348-2365.

28 Skokos D, Le Panse S, Villa I, Rousselle JC, Peronet R, David B, Namane A, Mecheri S: Mast cell-dependent B and $\mathrm{T}$ lymphocyte activation is mediated by the secretion of immunologically active exosomes. J Immunol 2001;166:868-876.

29 Nguyen DB, Ly TB, Wesseling MC, Hittinger M, Torge A, Devitt A, Perrie Y, Bernhardt I: Characterization of Microvesicles Released from Human Red Blood Cells. Cell Physiol Biochem 2016;38:1085-1099.

-30 Liu T, Mendes DE, Berkman CE: Functional prostate-specific membrane antigen is enriched in exosomes from prostate cancer cells. Int J Oncol 2014;44:918-922.

-31 Boelens MC, Wu TJ, Nabet BY, Xu B, Qiu Y, Yoon T, Azzam DJ, Twyman-Saint Victor C, Wiemann BZ, Ishwaran H, Ter Brugge PJ, Jonkers J, Slingerland J, Minn AJ: Exosome transfer from stromal to breast cancer cells regulates therapy resistance pathways. Cell 2014;159:499-513.

-32 Li Q, Shao Y, Zhang X, Zheng T, Miao M, Qin L, Wang B, Ye G, Xiao B, Guo J: Plasma long noncoding RNA protected by exosomes as a potential stable biomarker for gastric cancer. Tumour Biol 2015;36:2007-2012.

-33 Liu T, Zhang X, Gao S, Jing F, Yang Y, Du L, Zheng G, Li P, Li C, Wang C: Exosomal long noncoding RNA CRNDE-h as a novel serum-based biomarker for diagnosis and prognosis of colorectal cancer. Oncotarget 2016;7:85551-85563.

-34 Isin M, Uysaler E, Ozgur E, Koseoglu H, Sanli O, Yucel OB, Gezer U, Dalay N: Exosomal lncRNA-p21 levels may help to distinguish prostate cancer from benign disease. Front Genet 2015;6:168.

35 Wang J, Zhou Y, Lu J, Sun Y, Xiao H, Liu M, Tian L: Combined detection of serum exosomal miR-21 and HOTAIR as diagnostic and prognostic biomarkers for laryngeal squamous cell carcinoma. Med Oncol 2014;31:148.

-36 Thompson CA, Purushothaman A, Ramani VC, Vlodavsky I, Sanderson RD: Heparanase regulates secretion, composition, and function of tumor cell-derived exosomes. J Biol Chem 2013;288:10093-10099.

37 Xue M, Chen W, Xiang A, Wang R, Chen H, Pan J, Pang H, An H, Wang X, Hou H, Li X: Hypoxic exosomes facilitate bladder tumor growth and development through transferring long non-coding RNA-UCA1. Mol Cancer 2017;16:143.

-38 Mizutani K, Terazawa R, Kameyama K, Kato T, Horie K, Tsuchiya T, Seike K, Ehara H, Fujita Y, Kawakami K, Ito M, Deguchi T: Isolation of prostate cancer-related exosomes. Anticancer Res 2014;34:3419-3423.

-39 Tauro BJ, Greening DW, Mathias RA, Ji H, Mathivanan S, Scott AM, Simpson RJ: Comparison of ultracentrifugation, density gradient separation, and immunoaffinity capture methods for isolating human colon cancer cell line LIM1863-derived exosomes. Methods 2012;56:293-304. 


\section{Cellular Physiology Cell Physiol Biochem 2018;46:532-545

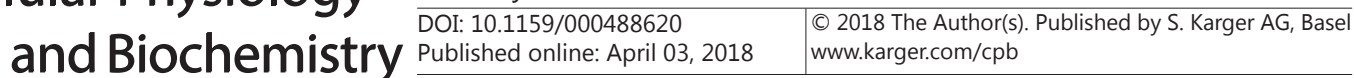 \\ Wang et al.: Diagnostic Potential of Tumor-Derived Exosomal LncRNAs in PCa}

-40 Zhou YG, Mohamadi RM, Poudineh M, Kermanshah L, Ahmed S, Safaei TS, Stojcic J, Nam RK, Sargent EH, Kelley SO: Interrogating Circulating Microsomes and Exosomes Using Metal Nanoparticles. Small 2016;12:727-732.

41 Andre F, Schartz NE, Movassagh M, Flament C, Pautier P, Morice P, Pomel C, Lhomme C, Escudier B, Le Chevalier T, Tursz T, Amigorena S, Raposo G, Angevin E, Zitvogel L: Malignant effusions and immunogenic tumour-derived exosomes. Lancet 2002;360:295-305.

42 Koga K, Matsumoto K, Akiyoshi T, Kubo M, Yamanaka N, Tasaki A, Nakashima H, Nakamura M, Kuroki S, Tanaka M, Katano M: Purification, characterization and biological significance of tumor-derived exosomes. Anticancer Res 2005;25:3703-3707.

43 Mathivanan S, Ji H, Simpson RJ: Exosomes: extracellular organelles important in intercellular communication. J Proteomics 2010;73:1907-1920.

\4 Rupp AK, Rupp C, Keller S, Brase JC, Ehehalt R, Fogel M, Moldenhauer G, Marme F, Sultmann H, Altevogt P: Loss of EpCAM expression in breast cancer derived serum exosomes: role of proteolytic cleavage. Gynecol Oncol 2011;122:437-446.

45 Zhang W, Ni M, Su Y, Wang H, Zhu S, Zhao A, Li G: MicroRNAs in Serum Exosomes as Potential Biomarkers in Clear-cell Renal Cell Carcinoma. Eur Urol Focus 2016

46 Yin CQ Yuan CH, Qu Z, Guan Q, Chen H, Wang FB: Liquid Biopsy of Hepatocellular Carcinoma: Circulating Tumor-Derived Biomarkers. 2016;2016:1427849.

-47 Skog J, Wurdinger T, van Rijn S, Meijer DH, Gainche L, Sena-Esteves M, Curry WT, Jr., Carter BS, Krichevsky AM, Breakefield XO: Glioblastoma microvesicles transport RNA and proteins that promote tumour growth and provide diagnostic biomarkers. Nat Cell Biol 2008;10:1470-1476.

48 Jin X, Chen Y, Chen H, Fei S, Chen D, Cai X, Liu L, Lin B, Su H, Zhao L, Su M, Pan H, Shen L, Xie D, Xie C: Evaluation of tumor-derived exosomal miRNA as potential diagnostic biomarkers for early stage nonsmall-cell lung cancer using next-generation sequencing. Clin Cancer Res 2017

-49 Rabinowits G, Gercel-Taylor C, Day JM, Taylor DD, Kloecker GH: Exosomal microRNA: a diagnostic marker for lung cancer. Clin Lung Cancer 2009;10:42-46.

50 Bottcher R, Hoogland AM, Dits N, Verhoef EI, Kweldam C, Waranecki P, Bangma CH, van Leenders GJ, Jenster G: Novel long non-coding RNAs are specific diagnostic and prognostic markers for prostate cancer. Oncotarget 2015;6:4036-4050.

51 Rajinikanth A, Manoharan M, Soloway CT, Civantos FJ, Soloway MS: Trends in Gleason score: concordance between biopsy and prostatectomy over 15 years. Urology 2008;72:177-182.

52 Chen N, Rong M, Shao X, Zhang H, Liu S, Dong B, Xue W, Wang T, Li T, Pan J: Surface-enhanced Raman spectroscopy of serum accurately detects prostate cancer in patients with prostate-specific antigen levels of 4-10 ng/mL. Int J Nanomedicine 2017;12:5399-5407. 